\title{
Micropropagation of selected materials of Opuntia ficus indica I through culture in vitro of areols
}

\begin{abstract}
Summary
In plant biotechnology, the use of in vitro culture of cells and tissues, offers the massive multiplication of a great diversity of plants, and dispose of those with excellent qualities from the phytosanitary point of view in addition to maintaining the characteristics of its genetic base. In nopal, for its high cellulose content, its use has now been directed as a successful alternative in the production of biofuels. The spread of nopales in a conventional way has been affected by the spread of serious phytopathological problems, including the onset of virous diseases. Therefore it was proposed as objectives, evaluates an in vitro protocol for the mass multiplication of nopal (Opuntia ficus-indica L), in order to apply it in different select opuntia materials, evaluate the effect of both cytokinins and auxins, estimated by a potential scale of plant production, and subsequently the sub-cultivation of areoles. Evaluating the effect of two cytokines and auxins in a basic MS medium (Murashige and Skoog, 1962), more vitamins and 9 different treatments combining 0.0, 2.0, 4.0 and $6.0 \mathrm{mg} . \mathrm{L}^{-1}$ kinetine $(\mathrm{K})$ and Benciladenine (BA) and 0.0, 0.2, 0.4 and 2.0 mg. ${ }^{\mathrm{L}-1}$ of naphthalen acetic acid (ANA) and indolacetic acid,(AIA) plus a witness treatment without regulators. The explants were incubated and maintained at a temperature of $25^{\circ} \mathrm{C}$ and a luminous intensity of $27.02 \mathrm{~m} \cdot \mathrm{m}^{-2} \mathrm{~s}^{-1}$, under a photoperiod of 16 light hours and 8 dark, for 16 weeks. The results obtained indicate that the culture medium supplemented with 2.0 $\mathrm{mgL}^{-1} \mathrm{BA}+0.2 \mathrm{mgL}^{-1} \mathrm{ANA}$ significantly favor the production of 6 new shoots per cultivated explant, obtaining up to 1296 plants per year. The plants obtained were successfully established and acclimatized, both in the greenhouse and in the field.
\end{abstract}

Volume 7 Issue 3 - 2020

\author{
Rodríguez-de la OJL, Ramírez-Pantoja PE \\ Department of Plant Science, Autonomous University Chapingo, \\ Mexico
}

Correspondence: Rodríguez-de la OJL, Professor, Department of Plant Science, Autonomous University Chapingo, México, Email jlrdelao@gmail.com

Received: April 12, 2020 | Published: June 26, 2020

Keywords: propagation, growth regulators, nopal, in vitro

Abbreviations: ANA, naphthalen acetic acid; K, kinetine; BA, benciladenine; AIA, indolacetic acid

\section{Introduction}

Globally Mexico has been characterized by being a very important country because it has a huge biodiversity that houses in terms of its biotic resources of both plants and animals, the above also confers an important endemism, which according to data from the National Commission for the Knowledge and Use of Biodiversity (CONABIO) are concentrated around 9500 endemic species, of which the family of cacti stands out. One of the most important species of this family is the nopal (Opuntia sp) of which Mexico is the leader in the production of nopal vegetables. In 2010, according to data from the National System of Phylogenetic Resources for Food and Agriculture (SINAREFI) $12,472.59$ hectares were registered from which 723,815.23 tons of fresh product were obtained. Which makes the country the main exporter of nopal, making it a very important crop. ${ }^{1-3}$

Nopal is considered one of nature's most versatile plants and with multiple forms of use especially in those regions with little yield of traditional annual crops. Its use ranges from strictly agricultural, both in human and livestock food, to industrial, cosmetic, medicinal to obtaining liquid and gaseous fuels. Nopal has advantages over other species since its high productive efficiency, wide range of adaptation, rapid growth and low input requirements, making it a viable energy option, since from its stems and fruits it is possible to obtain biogas, biodiesel and bioethanol or semi-finished products that can be used directly.

Today one of the major global problems is global warming, which is caused by the greenhouse effect. Most greenhouse gases come from the use of fossil fuels from automobiles, factories and electricity production. ${ }^{5}$ The gas responsible for most heating is carbon dioxide $\left(\mathrm{CO}_{2)}\right.$. Other gases that contribute to this effect are methane released by landfills and agricultural activity (especially the digestive systems of grazing animals), nitrous oxide from fertilizers, gases used for refrigeration and industrial processes, and the loss of forests that could otherwise store $\mathrm{CO}_{2}$ (National Geographic). The large amount of cellulose and fiber in cladodes is being seen as one of the best alternatives to obtain less polluting biofuel in nature. ${ }^{4-7}$

Today the human diet tends to be healthier so people seek to diversify their horticultural consumption. This causes the urban consumer to demand higher quality in food products. On the other hand, nopal for its high nutritional content and easy spread is an option for food in urban and rural areas of the country. The purpose of this research was to establish the in vitro conditions that would allow by growing areolas, obtaining and multiplying nopal plants. Evaluating in number of shoots, root, response types(callus, organ, both, none), height and diameter of the shoots. By using combinations of growth regulators benciladenine (BA)+naphthalenacetic acid (ANA), Kinetine $(\mathrm{KIN})+$ indolacetic acid (AIA), Benzyladenine (BA)+naphthalacetic acid (ANA)+kinetine (KIN). As well as evaluate the appropriate deinformation method (traditional and modified.

\section{Materials and methods}

Two methods of disinfestation were evaluated: the first consisted of vigorously washing the explants in commercial soap and three drops of tween 20 detergent; they were rinsed with normal water. They were subsequently immersed in $70 \%$ diluted alcohol for 3 minutes and rinsed with distilled water. They were then moved 
to a $20 \%$ sodium hypochlorite $(\mathrm{NaClO})$ solution and stirred for 20 minutes. They were immediately rinsed with oxygenated water $\left(\mathrm{H}_{2} \mathrm{Or}_{2}\right)$ at $30 \%$ for one hour. After that time, the explants were rinsed again with sterile water inside the previously disinfected laminar flow cabinet. Another desinfestation, process consisted of washing with commercial detergent and three drops of tween 80 detergent; they were subsequently placed in $70 \%$ ethanol for two minutes. They were then moved to a $10 \%$ sodium hypochlorite $(\mathrm{NaCl})$ solution for 10 minutes. They were immediately stirred with oxygenated water $\left(\mathrm{H}_{2} \mathrm{Or}_{2}\right)$ at $15 \%$ for 5 minutes. Subsequently, the explants were rinsed with sterile water inside the previously disinfected laminar flow hood.

Once the desinfestation processes were evaluated, experiments with growth regulators (auxins and cytokines) were established at different concentrations to stimulate in vitro sprouting and multiplication of nopal explants (Table 1).

Table I Concentrations in the different treatments

\begin{tabular}{|c|c|c|c|c|c|}
\hline Treat & Medium & $\begin{array}{l}\text { BA } \\
\text { (mg.L-1) }\end{array}$ & $\begin{array}{l}\text { ANA } \\
\left(\mathrm{mg} \cdot \mathrm{L}^{-1}\right)\end{array}$ & $\begin{array}{l}\text { KIN } \\
\left(\mathbf{m g} \cdot L^{-1}\right)\end{array}$ & $\begin{array}{l}\text { AIA } \\
\text { (mg.L-1) }\end{array}$ \\
\hline T0 & $M S * 100 \%$ & 0 & 0 & 0 & 0 \\
\hline TI & MSIO0 \% & 2 & 0.2 & 0 & 0 \\
\hline T2 & MSI00\% & 4 & 0.4 & 0 & 0 \\
\hline T3 & MSI00\% & 6 & 2 & 0 & 0 \\
\hline T4 & MSIO0 \% & 0 & 0 & 2 & 0.2 \\
\hline T5 & MSI00 \% & 0 & 0 & 4 & 0.4 \\
\hline T6 & MSIO0 \% & 0 & 0 & 6 & 2 \\
\hline T7 & MS I00\% & 2 & 0 & 6 & 0 \\
\hline T8 & MSIO0 \% & 4 & 0.2 & 4 & 0 \\
\hline T9 & MSI00\% & 6 & 0.4 & 2 & 0 \\
\hline
\end{tabular}

The variables evaluated were number of shoots and roots, formation of callus and organ, height and diameter of shoots, fork, and acclimatization. During this research, in vitro materials were incubated at a temperature of $26^{\circ} \mathrm{C}$ during the day and $22^{\circ}-24^{\circ}$ at night and a photoperiod of 16 hours of light intensity $(27.02 \mathrm{~mm}$ $\left.\mathrm{m}^{-2} \cdot \mathrm{s}^{-1}\right)$ and 8 hours of darkness.

The plants obtained were acclimatized in a glass greenhouse, $4 \mathrm{mx} 4 \mathrm{~m}$. Each plant was transplanted into a single-cell glass with peat moss, which was placed with a straw and a plastic bag. For four months, plant survival data was being taken to scale plant production. The escalation was carried out by taking on average the outbreaks obtained from the best treatments and related over time to determine the number of plants that would be obtained in a certain time frame. The experiment was conducted in a completely azar design. No 9 treatments were performed with 12 repetitions and a general witness. Quantitative results were analyzed using Minitab software ${ }^{\circledR}$ 17.1.0 v.13 (Minitab Inc. (C) by analyzing means of a factor with a $95 \%$ confidence level. The Tukey test was subsequently applied with a significance level of $0.05 .^{8}$

\section{Results and discussion}

Disinfestation method: The appropriate method for carrying out desinfestation in explants was the modified method, which showed $100 \%$ effectiveness in disinfecting explants without causing oxidation or necrosing. While under the traditional method all explants were necrotized. Responses types: Figure 1 shows the averages of the callus response, organogenesis, presence of both responses and unanswered explants in the different treatments. In organogenesis, the best concentration was $2.0 \mathrm{mgL}^{-1} \mathrm{KIN}+0.2 \mathrm{mgL}^{-1} \mathrm{AIA}$, this is due to the combination of a cytokinin (BA) and an auxin (AIA), this combination produces rapid cell division, usually small and undifferentiated cells. The concentration $6.0 \mathrm{mg} \mathrm{L}^{-1} \mathrm{BA}+2.0 \mathrm{mg} \mathrm{L} 1 \mathrm{KIN}+0.4 \mathrm{mgL}^{-1}$ ANA was the one that presented the highest percentage of calluses $(63 \%)$, this is consistent with what Rost (1998 mentions), in which it says that an intermediate concentration of cytokinins and a low concentration of auxins causes the cells to remain indifference, forming masses of tissue called calluses. This matches Rosa who noted that explants treated with Bencylamino purine (BAP) produced callus tissue, was not too abundant induction of sprouts.

Number of sprouts: After 16 weeks of incubation are presented in Figure 6. Statistical analysis showed that there are significant differences between the effects inducing treatments on that variable (p-value x 0.012). Treatment 1 , (MS $100 \%+2.0 \mathrm{mgL}^{-1} \mathrm{BA}+0.2 \mathrm{mgL}^{-1}$ ANA) average obtaining 5.57 sprouts by areola cultivated, standing out as the best response and according to the results and statistically exceeded treatments 3,(MS 100\%+6.0 $\mathrm{mgL}^{-1} \mathrm{BA}+2.0 \mathrm{mgL}^{-1}$ ANA) and4, (MS $100 \%+2.0 \mathrm{mgL}^{-1} \mathrm{KIN}+0.2 \mathrm{mgL}^{-1}$ AIA) whose results for this variable averaged 0.93 and 0.71 shoots per areola respectively; According to the results observed in treatment 1 , no statistically significant differences were observed with the rest of the treatments (Figure 1).

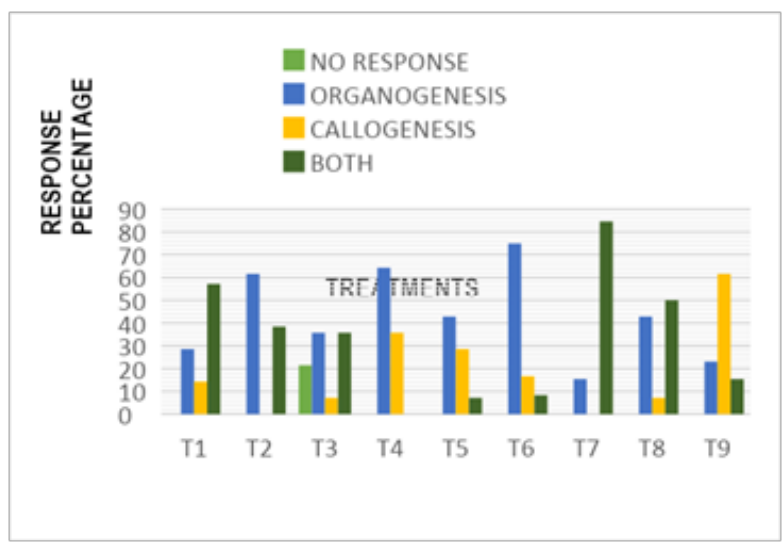

Figure I Response of explants to organogenesis and callogenesis in different treatments, at 16 weeks.

For the variable number of sprouts obtained in vitro, treatment with $2.0 \mathrm{mgL}^{-1}$ of $\mathrm{BA}+0.2 \mathrm{mgL}^{-1} \mathrm{ANA}$, significantly increased this response. These results were similary with that reported by Murashige ${ }^{6}$ in which they obtained the highest number of sprouts using $2.0 \mathrm{mgL}^{-1}$ BA (Figure 2). Other results on this variable are reported by Ojeda et al. ${ }^{7}$ who is obtained more development in Opuntia ficus-indica sprouts combining the BA:ANA at concentrations of $5.0 \mathrm{mg} . \mathrm{L}^{-1}$ and 0.25 mg. $L^{-1}$ respectively; Other results observed in the present research, was that by increasing the levels in the combination of BA:ANA or by changing BA to Kinetin, was less formation of new outbreaks is induced (Figure 3).

The length of sprouts: Figure 4 The results obtained with respect to the variable length of new sprouts obtained in vitro after 16 weeks of incubation. Statistical analysis showed that there are significant differences between the effects of treatments on the variable length of outbreaks $(-0.003)$. In treatment $6,(4.88 \mathrm{~cm})$ the longest length of sprouts was observed. The results in the statistical analysis showed no 
differences with those obtained in the treatments T1, T4, T5, T7 and T8. This response statistically exceded treatments 2,3 and $9,(1.5$, 1.40 , and $1.04 \mathrm{~cm}$ respectively). The length of the sprouts observed in treatment $6\left(100 \%+6.0 \mathrm{mg} \mathrm{MS}^{-1} \mathrm{KIN}+2.0 \mathrm{mgL}^{-1} \mathrm{AIA}\right)$, is due to the high concentration of cytokinins in the culture medium, this results coincides with Jankiewicz ${ }^{8}$ reported where it also stands out as a joint form that the presence of auxins stimulates do elongation and cell division.

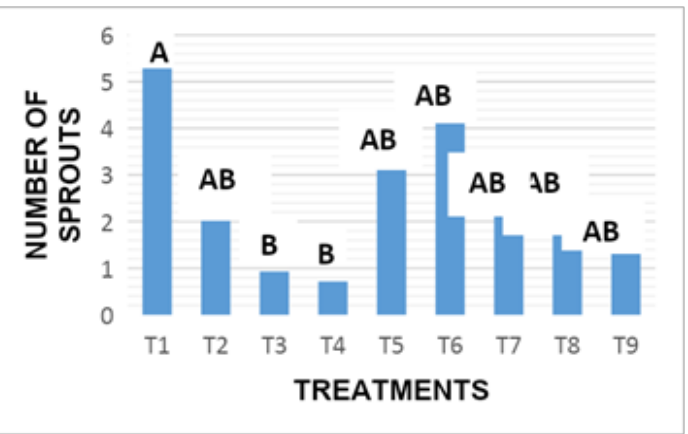

Figure 2 Response of explants to sprouting in different treatments at 16 weeks.

*Average with the same letter are statistically equal according to Tukey $\alpha=0.05$.

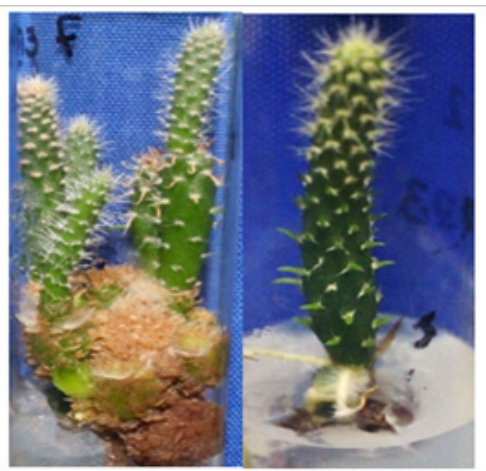

Figure 3 Explant response to the number of sprouts emitted by in vitro incubated nopal areola at 16 weeks

TI: MS 100\%+2.0 mg L-1BA+0.2 mg L-1 ANA, T4: MS 100\%+2.0 mg $L^{-1} \mathrm{KIN}+0.2 \mathrm{mg} \mathrm{L}^{-1} \mathrm{AIA}$.

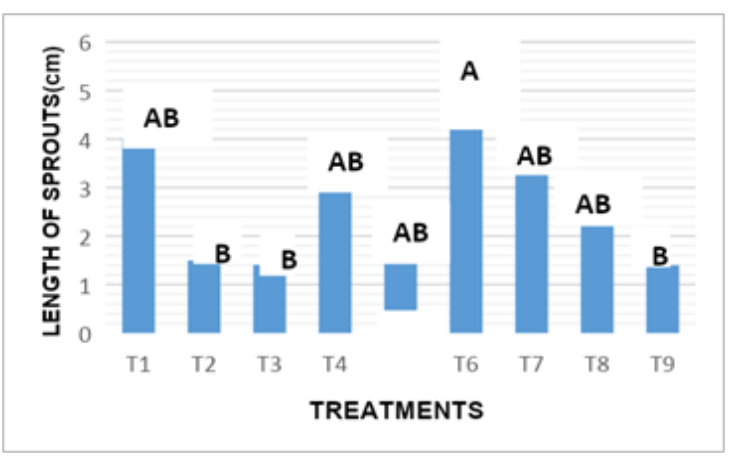

Figure 4 Length of new sprouts in vitro in the different treatments of in vitro culture at 16 weeks.

*Average with the same letter are statistically equal according to Tukey $\alpha=0.05$. TI : MS 100\%+2.0 mg L-1BA+0.2 mg L-1 ANA, T2: MS 100\%+4.0 mg L-1BA+0.4 mg L-1 ANA, T3: MS 100\%+6.0 mg L-1BA+2.0 mg L-1 ANA, T4: MS 100\%+2.0 $\mathrm{mg} \mathrm{L}{ }^{-1} \mathrm{KIN}+0.2 \mathrm{mg} \mathrm{L}^{-1} \mathrm{AIA}$, T5: MS $100 \%+4.0 \mathrm{mg} \mathrm{L} \mathrm{L}^{-1} \mathrm{KIN}+0.4 \mathrm{mg} \mathrm{L}^{-1} \mathrm{AIA}$, T6: MS $100 \%+6.0 \mathrm{mg} \mathrm{L}^{-1} \mathrm{KIN}+2.0 \mathrm{mg} \mathrm{L}^{-1} \mathrm{AIA}, \mathrm{T7}: \mathrm{MS} 100 \%+2.0 \mathrm{mg} \mathrm{L}^{-1} \mathrm{BA}+6.0 \mathrm{mg}$ $\mathrm{L}^{-1} \mathrm{KIN}, \mathrm{T} 8 \mathrm{MS} 100 \%+4.0 \mathrm{mg} \mathrm{L}^{-1} \mathrm{BA}+4.0 \mathrm{mg} \mathrm{L}^{-1} \mathrm{KIN}+0.2 \mathrm{mg} \mathrm{L}^{-1} \mathrm{ANA}$ y T9: MS $100 \%+6.0 \mathrm{mg} \mathrm{L}^{-1} \mathrm{BA}+2.0 \mathrm{mg} \mathrm{L}^{-1} \mathrm{KIN}+0.4 \mathrm{mg} \mathrm{L}^{-1} \mathrm{ANA}$.
Stem diameter: Figure 5 the statistical analysis performed showed that there are no significant differences between the effects inducing treatments on the variable diameter of stems $(-0.032)$. The results obtained in the culture medium used, and the combination of growth regulators as well as their respective doses in all treatments, showed no significant statistical difference between treatments for the variable diameter of the stem.

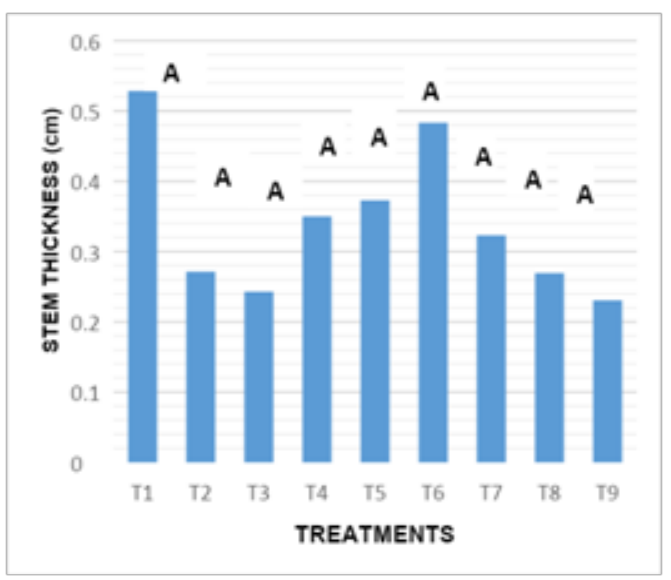

Figure 5 Response of the nopal stem diameter of the different in vitro culture treatments at 16 weeks.

TI: MS 100\%+2.0 mg L-1BA+0.2 mg L-1 ANA, T2: MS 100\%+4.0 mg L-1BA+0.4 $\mathrm{mg} \mathrm{L}^{-1}$ ANA, T3: MS 100\%+6.0 mg L-1BA+2.0 mg L-1 ANA, T4: MS 100\%+2.0 $\mathrm{mg} \mathrm{L}$ - $^{-1} \mathrm{KIN}+0.2 \mathrm{mg} \mathrm{L}^{-1} \mathrm{AIA}$, T5: MS $100 \%+4.0 \mathrm{mg} \mathrm{L}-1 \mathrm{KIN}+0.4 \mathrm{mg} \mathrm{L}^{-1} \mathrm{AIA}, \mathrm{T} 6$ : MS 100\%+6.0 mg L-1 KIN+2.0 mg L-1 AIA, T7: MS 100\%+2.0 mg L-1BA+6.0 mg $\mathrm{L}^{-1} \mathrm{KIN}$, T8: MS 100\%+4.0 mg L-1BA+4.0 $\mathrm{mg} \mathrm{L}^{-1} \mathrm{KIN}+0.2 \mathrm{mg} \mathrm{L}^{-1} \mathrm{ANA}$ y T9: MS $100 \%+6.0 \mathrm{mg} \mathrm{L}^{-1} \mathrm{BA}+2.0 \mathrm{mg} \mathrm{L}^{-1} \mathrm{KIN}+0.4 \mathrm{mg} \mathrm{L}^{-1} \mathrm{ANA}$.

Number of roots: Figure 6, the statistical analysis of the results revealed significant differences between treatments according to regulatory combinations and doses used on the root number variable $(-0.004)$. For this variable, the stems were subculture in vitro, in different treatments and combinations of growth regulators and in treatment 6 was presented on average 5.92 roots, standing out as the best response for the greatest number of roots obtained, surpassing the results obtained in treatment 9 , who showed no response when not presenting roots. For this variable under study, it was notable that in most treatments they had root development, so the analysis of statistics and their variance did not detect significant differences between them and are shown as statistically equal with treatment 6 . In the results obtained it was found that the combination KIN:AIA, was the presenting a better response towards the stimulation of a greater number of roots, and where the presence of auxins was highlighted, since independent of concentrations, it promotes the generation of roots in subcultured stems in vitro. Rosa showed, that the rooting of Turbinicarpus rioverdensis, T. schmiedickeanus subsp. gracilis and $T$. isabelae (species belonging to the family cactaceae), was performed in an efficient manner with the presence of auxins. Garcia reported that the maximum development of roots was added to the culture media indolbutyric acid (AIB). However, other results reported by Escobar, indicate that some concentrations and types of auxins induced the formation of callus in the basal part of the shoots cultivated in vitro conditions.

Bifurcation of stems: Figure 7 shows the incidence of stems with bifurcation in the different treatments. The bifurcation of stems obtained in vitro is an important variable, since for each fork allows us to have a new sprouts, to be grown in vitro, highlighting treatment7, in 
which $15.4 \%$ of the stems presented up to three new sprouts (shoots) per cultivated stem, in most treatments they had $30.8 \%$ of new shoots through the bifurcation. Treatment 1 , showed $7.14 \%$ in bifurcation by one stem cultivated and $7.14 \%$ with two new sproutss, giving a total of $14.28 \%$ response of new shoots through the bifurcations presented on the stems. Treatments 4 and 5 showed only a news sprouts of $7.14 \%$ and $9.1 \%$ respectively (Figure 8 ). The rest of the treatments showed no significant difference between treatments and this variable of new shoots through the bifurcation of the stems grown in vitro. The response to the emission of new shoots by cultivated stem, observed in treatment 7 , was basically stimulated by the presence of type cytokinin's and concentration in the culture medium, this response was also reported by Jankiewicz ${ }^{8}$ who reported that in many explants grown in vitro usually the addition of cytokines promote the sprouting of axillary buds, and stimulate the expansion of leaves in addition to retardation. ${ }^{9}$

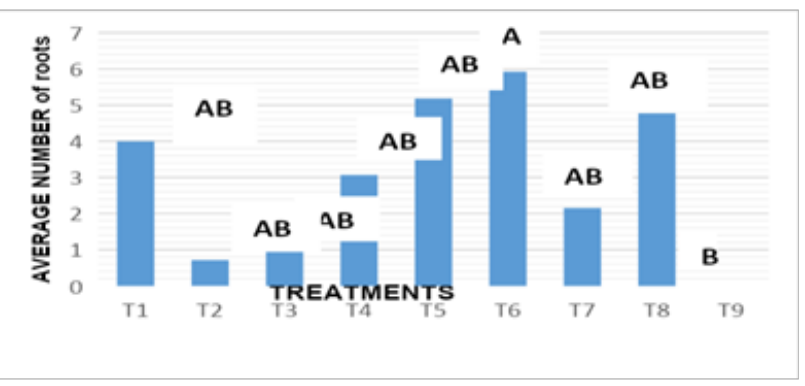

Figure 6 (a)Response of the number of nopal roots to the different in vitro culture treatments at 16 weeks.

TI: MS 100\%+2.0 mg L-1BA+0.2 mg L-1 ANA, T2: MS 100\%+4.0 mg L-1BA +0.4 mg L-1 ANA, T3: MS 100\%+6.0 mg L-1BA+2.0 mg L-1 ANA, T4: MS 100\%+2.0 $\mathrm{mg} \mathrm{L} L^{-1} \mathrm{KIN}+0.2 \mathrm{mg} \mathrm{L}^{-1} \mathrm{AIA}, \mathrm{T5}$ : MS $100 \%+4.0 \mathrm{mg} \mathrm{L}^{-1} \mathrm{KIN}+0.4 \mathrm{mg} \mathrm{L}^{-1} \mathrm{AIA}, \mathrm{T6}$ : MS 100\%+6.0 mg L-1 KIN+2.0 mg L-1 AIA, T7: MS 100\%+2.0 mg L-1BA+6.0 mg $L^{-1} \mathrm{KIN}, \mathrm{T} 8: \mathrm{MS} 100 \%+4.0 \mathrm{mg} \mathrm{L}^{-1} B A+4.0 \mathrm{mg} \mathrm{L}^{-1} \mathrm{KIN}+0.2 \mathrm{mg} \mathrm{L}^{-1} \mathrm{ANA}$ y T9: MS $100 \%+6.0 \mathrm{mg} \mathrm{L}^{-1} \mathrm{BA}+2.0 \mathrm{mg} \mathrm{L}^{-1} \mathrm{KIN}+0.4 \mathrm{mg} \mathrm{L}^{-1} \mathrm{ANA}$.

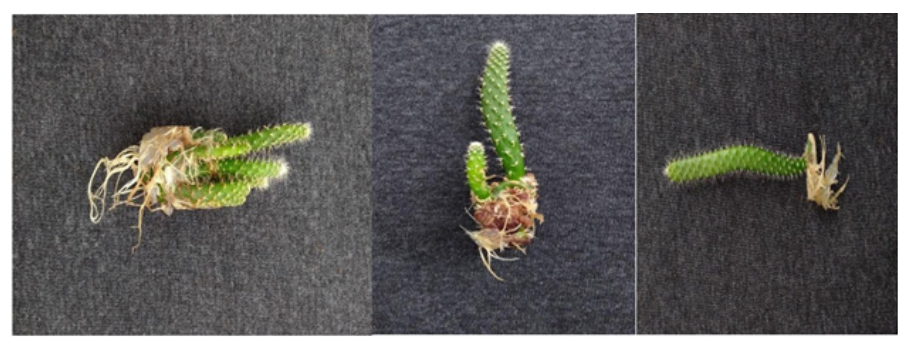

Figure 6(b) Response in rooting to different in vitro culture treatments at 16 weeks.

T6: MS 100\%+6.0 mg L-1 KIN+2.0 mg L-1 AIA, T8: MS 100\%+4.0 mg L-1 BA+4.0 $\mathrm{mg} \mathrm{L}^{-1} \mathrm{KIN}+0.2 \mathrm{mg} \mathrm{L}^{-1} \mathrm{ANA}$ y $\mathrm{T} 9: \mathrm{MS} 100 \%+6.0 \mathrm{mg} \mathrm{L}^{-1} \mathrm{BA}+2.0 \mathrm{mg} \mathrm{L}^{-1} \mathrm{KIN}+0.4$ $m g L^{-1} A N A$.

Acclimatization: Nopal plantlets obtained in vitro and rooted were transferred to greenhouse conditions to be acclimatized and basically plant survival rates were assessed. Figure 9 shows the growth of plants during acclimatization in the greenhouse and field. The nopal plants obtained in vitro conditions for acclimatization, were placed in a peat moss substrate and without additional nutrients, showing $100 \%$ survival. This stage of plant acclimatization was also reported by Bhau ${ }^{10}$ obtaining the same stage survival of Coryphantha elephantidens Lem plants (Figure 10). We can observe the acclimatization and development of plants in the greenhouse.

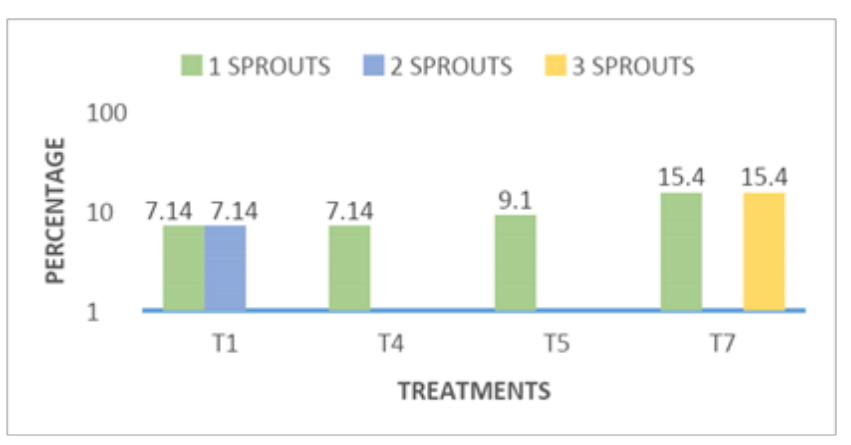

Figure 7 Response of the number of bifurcations per nopal sprout grown in vitro to treatments I, 4, 5, and 7 , at 16 weeks.

TI:MS 100\%+2.0 mg L-1BA+0.2 mg L-1 ANA, T4: MS I00\%+2.0 mg L-1 KIN+0.2 $\mathrm{mg} \mathrm{L}^{-1}$ AIA, T5: MS 100\%+4.0 mg L-1KIN+0.4 mg L-1 AIA y T7: MS 100\%+2.0 $m g L^{-1} B A+6.0 \mathrm{mg} \mathrm{L}^{-1} \mathrm{KIN}$

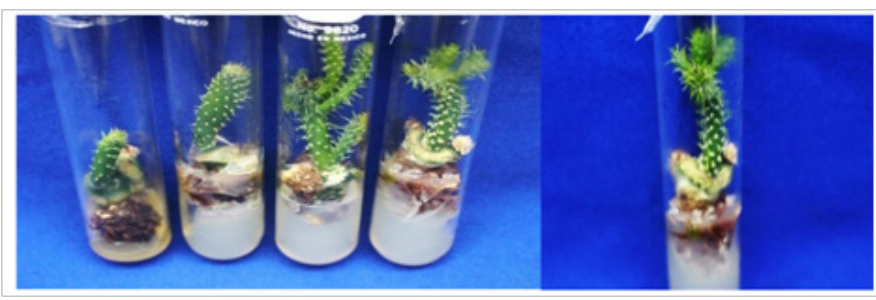

Figure 8 (a) New Sprouts emitted by areol of nopal incubated in vitro in treatment in 7 at 16 weeks.

T7: MS $100 \%+2.0 \mathrm{mg} \mathrm{L}^{-1} \mathrm{BA}+6.0 \mathrm{mg} \mathrm{L}^{-1} \mathrm{KIN}$

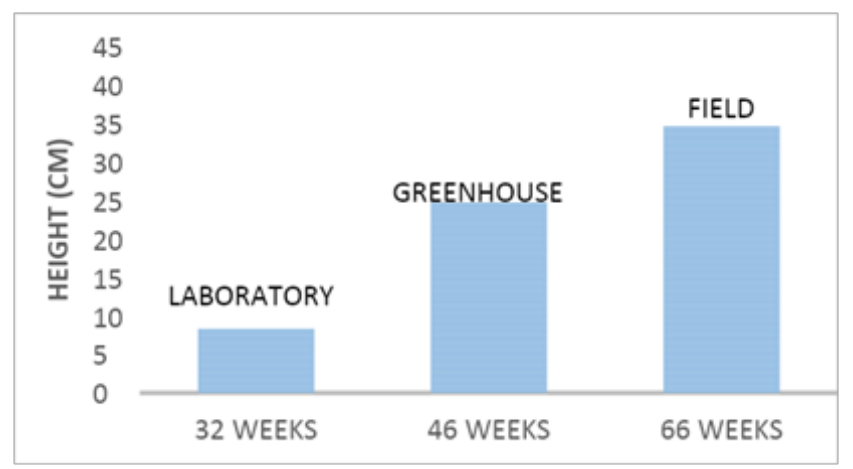

Figure 8 (b) Growth of nopal plants at different growing sites.

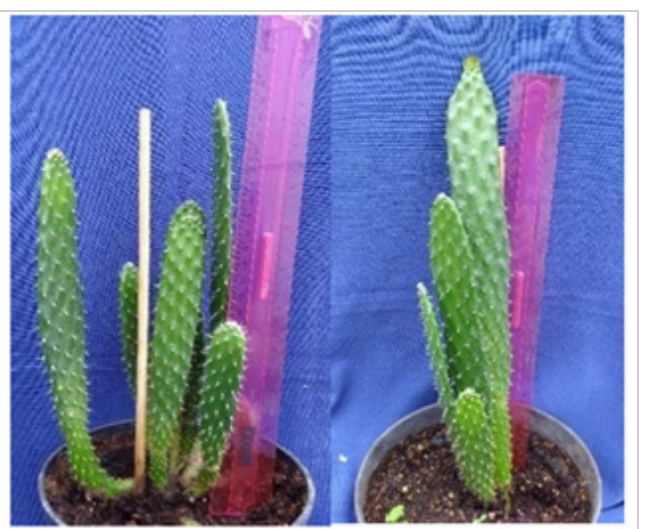

Figure 9 Plants acclimatized in the greenhouse after 46 weeks of being planted. 


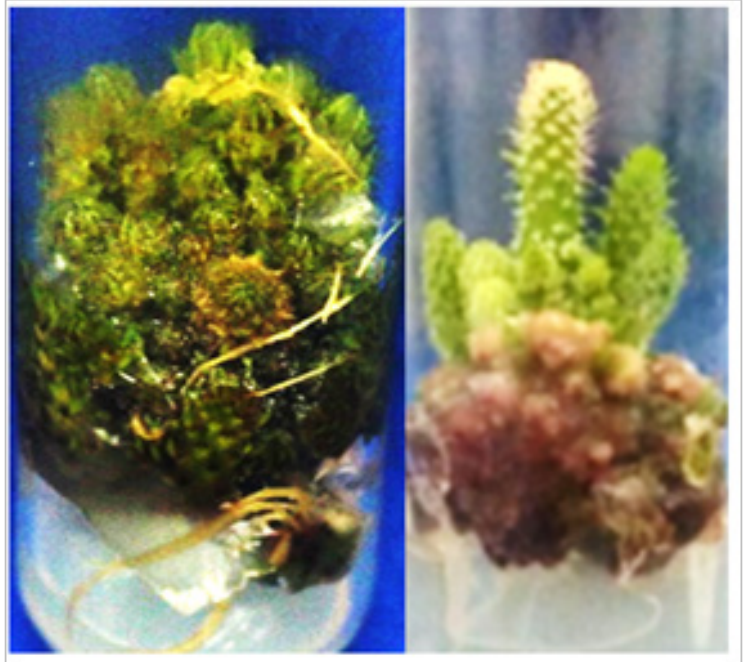

Figure 10 Treatment with better response, for multiple obtaining of sprouts in nopal.

TI : MS I00\%+2.0 mg L-1BA+0.2 mg L-1 ANA, T5: MS 100\%+4.0 mg L-1 KIN+0.4 $\mathrm{mg} \mathrm{L}^{-1} \mathrm{AIA}$,

Zhuang et al. ${ }^{11}$ remedied $90 \%$ survival in the acclimatization stage of Opuntia ficus-indica plants in the greenhouse. Escobar et al. ${ }^{12}$ they obtained $100 \%$ survival in soil transplantation to soil of Opuntia amyclaea, and in other species of Turbinicarpus were obtained for this same stage plant survival in 65 to $98 \%$. In some cacti such as Notocactus, acclimatization is a critical process and sometimes only a survival of $20 \%$ Medeiros et $\mathrm{al}^{4}{ }^{4}$ is reported. Finally, the plants obtained from nopal already acclimated, were taken to the field of "La Nopalera", located in the Experimental Agricultural Field of the Autonomous Chapingo University.

Plant production scaling: The estimate consists of obtaining and multiplication plants that can potentially be obtained exponentially from an explant (areola) cultivated in vitro, the results obtained for nopal, allowed to calculate the amount of plants that can be obtained in a certain time (one year), taking as a reference in this work the highest average regeneration of new shoots that was 5.57 shoots, which was taken as 6. Applying the following data allow estimate the number of plants that could theoretically be obtained in 14 weeks.

\section{$\mathrm{Nbci}=\mathrm{X}$}

In: $\mathrm{Nb}$, number of average outbreaks obtained from a bud; $c i$, cycle where $\mathrm{i}=0,1,2,3 \ldots$ Each cycle includes 14 weeks; $X$, plants obtained.

In the scale of production of in vitro nopal plants, it can be estimated that in one year, up to 1296 shoots(plants) could be obtained from a single yolk (theoretically). It is of great importance since in addition to maintaining the genetic basis of the plants obtained you can have plants of excellent phytosanitary quality free of pathogens. In this research the estimated data are mainly presented the average results for each of the variables studied, although there were other responses that exceed the estimated data, since for example, in treatments 5 and 6 , some subcultured stems in vitro (explants)) developed up to 26 and 20 new shoots, respectively (Figure 10).

For treatment $5\left(100 \%+4.0 \mathrm{mg} \mathrm{MS} . \mathrm{L}^{-1} \mathrm{KIN}+0.4 \mathrm{mg} . \mathrm{L}^{-1} \mathrm{AIA}\right)$ a stem was obtained, a maximum regeneration potential of up to26new shoots per subculture areola. Given this data, you can obtain and multiply a huge number of sprouts. Thus an example of scaling production of nopal plants over a year. This report coincides with Rosa et al., ${ }^{9}$ in the species T. pseudomacrochele subsp. lausseri, in which an average of 26.3 sprouts per explant was obtained in the same period, using in this case $3.33 \mathrm{mg} . \mathrm{L}^{-1}$ bencilaminopurine (BAP). According to the reasoning described above, with this efficiency it would be possible, in theory, to generate more than 300-106 outbreaks in the same time.

\section{Conclusion}

The best process of explant desinfestation was determined, managing to establish an effective cleaning method, free, of fungi and bacterium. The formation of new sprouts was obtained in a $100 \% \mathrm{MS}$ medium supplemented with $6.0 \mathrm{mgL}^{-1} \mathrm{KIN}+2.0 \mathrm{mgL}^{-1} \mathrm{AIA}$. The highest number of sprouts was obtained in a $100 \%$ MS medium supplemented with $2.0 \mathrm{mgL}^{-1} \mathrm{BA}+0.2 \mathrm{mgL}^{-1} \mathrm{ANA}$. The in vitro strategies used, allow to obtain, and multiply plants on an important scale in the short term, but also preserve the original genetic characteristics of the plants. The longest stem length and number of roots was obtained in a 100\% MS medium supplemented with $6.0 \mathrm{mgL}^{-1} \mathrm{KIN}$ (cytokinin) $+2.0 \mathrm{mgL}^{-1} \mathrm{AIA}$ (auxin).According to the results obtained, the scaling of production of in vitro plants of nopal, in the four cycles per year is 1294 plants, from a single explant. and potentially can get up to 456,976 outbreaks in a year.

\section{Acknowledgments}

None.

\section{Conflicts of interest}

The author declares that there is no conflict of interest.

\section{Funding}

None.

\section{References}

1. Alvarado BE, Cháble MF, Morán VN, et al. In vitro regeneration and Proximal Analysis of Nopal Opuntia ficusindica COPENA 1. Instituto Tecnológico de Roque, Celaya, Guanajuato; 2007.

2. Giusti P, Vitti D, Fiocchetti F, et al. In vitro propagation of three endangered cactus species. Sci Hort. 2002;95(4):319-332.

3. Leifert C, Morris CE, Waites WM. Ecology of microbial saprophytes and pathogens in tissue culture and field grown plants: Reason for contamination problems in vitro. Critical Reviews in Plant Sciences. 1994. p. 139-183.

4. Medeiros LA, Roberval-Cassia SR, Gallo LA, et al. In vitro propagation of Notocactus magnificus. Plant Cell Tiss Org Cult. 2006;84:165-169.

5. Vidales FI. Effect of Growth Regulators on The Processes of Organogenesis and Somatic Embriogenesis of Avocado Persea Americana Mill. (Doctoral thesis) University of Colima. Colima Mexico; 2002.

6. Murashige T, Skoog F. A revised medium for rapid growth and bioassays with tobacco tissue cultures. Physiol Plant. 1962;15:37-397.

7. Ojeda $\mathrm{MC}$, Vázquez $\mathrm{AR}$, Rodríguez $\mathrm{FH}$. In vitro establishment of Nopal Opuntiaficus-indica. Faculty of Agronomy. Autonomous University of Nuevo León. Journal of Public Health and Nutrition. 2010 .

8. Jankiewcz SJ. Regulators of growth, development and resistance in plants. Department of Phytotechnics. Horticulture Institute. Chapingo Autonomous University; 2003. 
9. Rosa Carrillo ML, Pérez-Molphe-Balch E. In vitro propagation of eight species or subspecies of Turbinicarpus (Cactaceae). In Vitro Cell Dev Biol Plant. 2005;41:540-545.

10. Bhau BS. Regeneration of Coryphanthaelephantidens (Lem.). (Cactaceae) from root explants. Scientia Horticulturae. 1999;81(3):337-344.
11. Zhuang T, Zhang J, Yu J. Studies on the rapid propagation of Opuntia ficus-indica Mill via tissue culture. Journal of Shanghai Jiaotong University Agricultural Science. 2004;22(3):313-315.

12. Escobar AHA, Villanueva AVM, Villegas MA. Opuntia micropropagatión by axillary proliferation. Plant Cell Tissue and Organ Culture. 1986. 277 p. 